\title{
O direito à educação e o cotidiano escolar: dimensões do concebido, do vivido e do percebido*
}

\author{
The right to education and daily life school: \\ dimensions of conceived, lived and conceived \\ El derecho a la educación y el cotidiano escolar: \\ dimensiones de lo concebido, de lo vivido y de lo percebido
}

NILDA STECANELA**

$\rightarrow$

\begin{abstract}
RESUMO
O foco deste texto emerge das inquietações que perpassam o cotidiano das instituições educativas, identificadas em categorias analíticas emergentes de pesquisa que teve como corpus empírico as narrativas de professores e de alunos da educação básica. Constitui uma tentativa de interpretação dos ecos das palavras dos interlocutores envolvidos ao referirem, de modo indireto, que a obrigatoriedade da frequência à escola produz uma configuração social que altera as rotas do projeto moderno de escola. E afeta também a relação pedagógica e as culturas escolares neste evidenciadas. Objetiva, portanto, a tessitura de relações a respeito do paradoxo "direito à educação e escolarização obrigatória" em diálogo com as evidências do processo de mutação da escola. Contextualiza os direitos humanos e o direito à educação em interlocução com os conceitos de configuração social e relações de interdependência, buscados em Norbert Elias sobre o processo civilizador. Michel de Certeau e Roger Chartier contribuem, respectivamente, na discussão através dos conceitos de estratégia e de tática, assim como de representação social.

Palavras-chave: Direito à educação. Cotidiano escolar. Relação pedagógica. Diversidade sociocultural.
\end{abstract}

\begin{abstract}
The focus of this paper emerges from the concerns that pervade the daily life of educational institutions, which are identified through emerging analytical categories of research that have as their empirical corpus the narratives of teachers and students at the elementary and secondary school level. This paper attempts to interpret the echoes of the words of teachers and students and indirectly refers to the fact that mandatory school attendance produces a social configuration that changes the directions of the modern school project, affecting pedagogical relationship and school cultures. The paper analyses the fabric of the relations regarding the paradox of the "right to education and compulsory schooling" and dialogues with the evidence of changing processes in schools. It contextualises human rights and the right to education in dialogue with the concepts of social configuration and interdependent relationships contained in the theory about the civilising process developed by Norbert Elias. The ideas of Michel de Certeau and Roger Chartier are also used to contribute to the discussion regarding concepts of strategy and tactics, respectively, as well as in terms of social representation.
\end{abstract}

Keywords: Right to education. Everyday school life. Pedagogical relationship. Sociocultural diversity.

\section{RESUMEN}

El foco de este texto emerge de las inquietudes presentes en el cotidiano de las instituciones educativas, identificadas en categorías analíticas emergentes de investigación que tuvo como corpus empírico las narrativas de profesores y de alumnos de la Educación Básica. Constituye una tentativa de interpretación de los ecos de las palabras de los interlocutores involucrados al mencionar, de modo indirecto, que la obligatoriedad de la frecuencia a la escuela produce una configuración social que altera las rutas del proyecto moderno de escuela, afectando la relación pedagógica y las culturas escolares evidenciadas. Objetiva, por tanto, tejer relaciones a respecto de la paradoja "derecho a la educación y escolarización obligatoria" en diálogo con las evidencias del proceso de cambio de la escuela. Contextualiza los derechos humanos y el derecho a la educación en interlocución con los conceptos de configuración social y relaciones de interdependencia, buscados en Norbert Elias sobre el proceso civilizador. Michel de Certeau y Roger Chartier contribuyen, respectivamente, en la discusión a través de los conceptos de estrategia y de táctica, así como de representación social.

Palabras clave: Derecho a la educación. Cotidiano escolar. Relación pedagógica. Diversidad sociocultural.

\footnotetext{
*O presente texto vincula-se ao Projeto Matriz “Observar a escola e suas margens: perspectivas plurais em diálogo - Fase II”, financiado pelo CNPq, e aos subprojetos que a partir deste se desdobram, designadamente o Projeto Capes de Estágio Pós-Doutoral de título homônimo ao texto, desenvolvido na UCL Institute of Education, London. No âmbito desse último, compete assinalar a leitura crítica e as valiosas observações feitas por Tristan McCowan, supervisor no Estágio Pós-Doutoral, a quem, naturalmente, reitera-se muitos agradecimentos. Entretanto, sublinha-se que qualquer deficiência que o texto possa conter é de exclusiva responsabilidade da autora do mesmo.

**Doutora em Educação, Universidade de Caxias do Sul. E-mail: <nildastecanela@gmail.com>.
} 


\section{INTRODUÇÃO}

Considerando a história da humanidade, a discussão sobre os direitos humanos é recente, sendo potencializada somente após a Segunda Grande Guerra. A Declaração Universal dos Direitos Humanos é um marco que inaugura a Era dos Direitos (BOBBIO, 1992). O direito à cidadania se desdobra em um conjunto de direitos que perpassam os direitos civis, políticos e sociais. Já o direito à educação situa-se no conjunto dos direitos sociais e é considerado um direito mediador para a garantia dos demais direitos. Segundo Cury (2002, p. 246), "a educação escolar é uma dimensão fundante da cidadania, e tal princípio é indispensável para políticas que visam à participação de todos nos espaços sociais e políticos e, mesmo, para reinserção qualificada no mundo profissional do trabalho".

$\mathrm{O}$ direito à educação no Brasil é assegurado na Constituição Federal, a qual proclama a educação como um direito social ${ }^{1}$. A Constituição de 1988 acata o direito à educação como direito público subjetivo, embora o ensino fundamental já fosse considerado como um direito juridicamente protegido desde 1934 (CURY, 2002). Como um bem público, a educação é cercada de proteção, associada a um sistema de garantia do direito à educação, agregando um conjunto de leis e convenções que regem e que zelam pelo cumprimento do acordado legalmente, elencado por Cury como sendo a Lei de Diretrizes e Bases da Educação Nacional (LDB), o Plano Nacional de Educação (PNE), os pareceres e as resoluções dos Conselhos de Educação, aos quais acrescentamse o Estatuto da Criança e do Adolescente (ECA) e as Diretrizes Curriculares Nacionais para a Educação Básica.

Desde abril de 2013, a legislação educacional brasileira garante o direito de acesso a 14 anos de escolarização obrigatória para toda população com idades compreendidas entre os 4 e os 17 anos, incluindo a educação infantil (dois anos), o ensino fundamental (nove anos) e o ensino médio (três anos). O Brasil ultrapassou a cifra dos $95 \%$ de garantia de acesso à escola para crianças e jovens em idade escolar, sendo um indicador de efetivação do direito à educação, entretanto, ainda é elevado o número daqueles que experimentam o insucesso escolar e/ou abandonam a escola precocemente.

Cabe problematizar o direito à educação traduzido simplificadamente pela garantia do acesso, pois as convenções internacionais são específicas no tocante às formas institucionais que devem garantir a educação e a duração desta, mas silenciam no tocante aos processos a serem desenvolvidos. Para McCowan (2011), os riscos de uma associação unilateral da educação com a escolaridade podem acarretar uma desconsideração da dimensão da

\footnotetext{
1 Ver Constituição Federal de 1988, artigos 6o e 205.
}

experiência que acompanha os modos como o ensino e a aprendizagem acontecem, deixando em segundo plano o direito à aprendizagem.

Observou-se que, na área da educação voltada aos direitos humanos e ao direito à educação no Brasil, há uma produção significativa sobre ambos na dimensão do concebido. Uma relativa produção com análises que problematizam o vivido, especialmente voltada à formação de professores para os direitos humanos, e uma restrita abordagem sobre como os atores do cotidiano escolar percebem os efeitos da era dos direitos em suas trajetórias profissionais e escolares. Esses elementos contextualizam os objetivos do texto, com atenção centrada nas dimensões do percebido e com reflexões originadas na problematização dos resultados de projeto de pesquisa que observou a escola e suas margens em uma perspectiva dialógica plural. E cujo objeto procurou focar os sentidos atribuídos à experiência escolar e docente.

Concebido, vivido e percebido são categorias analíticas utilizadas por inspiração nas elaborações de Lefebvre (1971), adaptadas ao contexto desta pesquisa, considerando as dimensões mental, experiencial e social do conceito de espaço na vida cotidiana. Lefebvre refere que o conceito de espaço denota e conota todos os espaços possíveis: abstrato ou real, mental ou social. Assim, o concebido é considerado um espaço abstrato, mental, legal e burocrático, pensado previamente por profissionais e tecnocratas. O espaço vivido é o da experiência prática da vida cotidiana, difícil de ser apreendido porque envolve o imaginário e o simbólico, com suas complexidades nem sempre passíveis de serem analisadas pela teoria. Por sua vez, o percebido, considerado um espaço social, apresenta-se pelos órgãos dos sentidos, mas também através do mundo incorporado pelas práticas sociais, na relação com as materialidades que as compõem. De modo simplificado, na analogia utilizada no texto, o concebido pode ser entendido com uma proximidade à história oficial; o vivido pode ser associado às práticas cotidianas das e nas instituições de socialização; e o percebido pode ser referido aos sentidos atribuídos pelos sujeitos às suas trajetórias.

O estudo iniciado em 2011, financiado pelo CNPq e atualmente em segunda fase de desenvolvimento, tem como cenário de pesquisa escolas públicas localizadas em municípios da serra do Rio Grande do Sul e, como interlocutores empíricos, professores e alunos do ensino fundamental e médio. Uma centena de professores e alunos de ambos os níveis participaram da pesquisa através de questionário autoaplicado. Além desses, 50 alunos do ensino fundamental, do sexto e do nono ano, colaboraram no estudo com respostas a um questionário estruturado. O trabalho de campo envolveu ainda registros etnográficos e realização de entrevistas narrativas com 
10 professores e 10 alunos. Desse modo, as representações trazidas pelos atores dos processos educativos em relação aos processos de mutação da escola e aos efeitos do direito à educação no cotidiano das instituições de socialização, especialmente na escola, foram categorias analíticas privilegiadas na tematização.

As questões orientadoras do estudo procuraram relacionar o cenário educacional brasileiro das últimas três décadas, desde a implantação da escolarização obrigatória, com as políticas educacionais. Entre as indagações formuladas, citam-ses as que vêm a seguir. Em que medida os princípios presentes nos documentos que fundam e dão movimento ao que se chama de sistema de diretos à educação no Brasil têm sido efetivados para além da garantia do acesso? Como os atores da escola percebem esses princípios e como os traduzem na relação pedagógica? Quais indícios do projeto moderno de escola ainda se fazem presentes nas práticas docentes? Quais sinais da mutação da escola podem ser evidenciados nas narrativas e nas práticas dos seus atores? Quais as evidências da travessia entre o direito à educação e o direito à aprendizagem?

A postura investigativa que permeou a proposição e o desenvolvimento do projeto acolhe uma pluralidade de ângulos de observação para o cotidiano da escola e suas interfaces. Os procedimentos utilizados na construção dos dados e resultados da investigação baseiam-se na concepção de um diálogo em três dimensões: entre o objeto e o problema de pesquisa, entre os interlocutores empíricos e entre os interlocutores teóricos.

Considerando o exposto, o texto se organiza em três tópicos. No primeiro, traz a descrição dos dados empíricos com as narrativas sobre a experiência docente e escolar. No segundo, procura interpretar os ecos das palavras dos interlocutores empíricos, trazendo as contribuições dos interlocutores teóricos em interface com os objetivos e indagações que motivaram o estudo. E por último, sintetiza os achados da pesquisa e procura tecer algumas recomendações.

\section{NARRATIVAS SOBRE O VIVIDO E SOBRE O PERCEBIDO NO COTIDIANO DA ESCOLA}

Os dados da pesquisa sublinharam a presença do que se denomina de culturas da reclamação, tanto por parte dos professores (em relação aos alunos, à família e às políticas educacionais) como dos alunos, sobretudo daqueles matriculados nos últimos anos do ensino fundamental e médio (em relação à escola, os professores e o mundo adulto). As narrativas produzidas relacionam-se à forma como os colaboradores da pesquisa percebem suas experiências docentes e escolares (percebido), considerando as trajetórias protagonizadas no espaço escolar (vivido) e no contexto das políticas educacionais voltadas ao direito à educação e à escolarização obrigatória (concebido).

Quanto à sociografia da amostra, todos os professores possuem formação em nível superior ou pós-graduação, concluída ou em curso, a maioria desempenha a função docente em 40 horas semanais e a concentração da faixa etária é até os 40 anos de idade, sendo que $90 \%$ do total pertence ao sexo feminino. Os alunos pertencem às classes média baixa e baixa, têm entre 11 e 19 anos, participam em equilíbrio entre os sexos, um percentual abaixo dos $20 \%$ trabalha em meio período, notadamente nos anos finais do EF e ao longo do EM e, quanto à origem étnica, há uma predominância dos ítalo, luso e afrodescendentes.

\subsection{As narrativas dos professores ${ }^{2}$}

Provocados a refletir sobre os desafios da educação contemporânea, da atuação docente e da organização curricular em tempos de direito à educação, em resposta a uma questão aberta - portanto, sem direcionamento e com a intencionalidade da produção de uma narrativa espontânea -, os professores sublinharam, entre muitos aspectos, pontos que consideram dificultar sua ação docente e desqualificar a educação praticada no país. São eles: desmotivação e falta de interesse dos alunos; fronteiras borradas entre o educar e o ensinar, entre o papel da família e o da escola; obrigatoriedade na frequência à escola, mesmo para aqueles que "não querem aprender"; distanciamento da escola pública em relação às Tecnologias da Informação e da Comunicação (TICs).

\section{Os alunos não têm interesse nas aulas e estão desmotivados}

A propósito do primeiro aspecto mencionado, os professores produzem narrativas direcionadas à falta de interesse e desmotivação dos alunos pelas aulas. $\mathrm{Na}$ maioria das ocorrências, um discurso de culpabilização aponta serem os alunos os únicos protagonistas da relação pedagógica, como refere a narrativa da professora a seguir: "Hoje em dia, os alunos são mais difíceis de lidar, têm menos empenho e esforço. Só interessa a eles o diploma final. Muitos são obrigados pelos pais a virem para a escola. Quando eu estudava, a média era 7, e poucos eram os que reprovavam. Precisávamos estudar muito. Hoje, a média é baixa, tem um monte de oportunidades e chances e a maioria nem aproveita". Os professores produzem narrativas considerando seus próprios percursos e tendo os sentidos que atribuíram a sua escolarização como ponto de conexão para julgarem os sentidos que seus alunos conferem à escola.

\footnotetext{
2 Optou-se por não codificar as narrativas dos professores, devido à pequena diferenciação entre as produções, nos recortes de sexo, na formação ou no nível de atuação.
} 
O reconhecimento da falência do projeto moderno de escola, centrado na ação do professor e na transmissão da informação, aparece travestido nas narrativas de vários participantes, ecoando um sentimento coletivo: "Um dos maiores desafios da escola contemporânea é 'entreter' o aluno, fazer com que ele se interesse pelo tema/assunto que os professores propõem. Minhas maiores dificuldades são lidar com o comportamento dos alunos desinteressados em sala de aula".

A percepção de uma adesão distanciada dos alunos em relação à escola, a falta de motivação para frequentar as aulas e para fazer o que é proposto, ao mesmo tempo em que parece naturalizar-se nas narrativas dos professores, comunica um apelo sobre o que fazer e como proceder para reverter a situação ou para sintonizar (com sentido de reconectar) a relação pedagógica. Percebe-se a denúncia, mas, também, uma espécie de conformismo com o atual cenário educativo, nas palavras de um dos professores: "O maior desafio ou problema na escola atual é despertar o interesse do aluno para a leitura, para o conhecimento, porque muitos deles estão 'acomodados', sem ânimo, vontade de aprender".

Em raras vezes, as reflexões associam de modo indireto aspectos da atuação docente e da falta de recursos para o desenvolvimento de aulas mobilizadoras, conforme evidencia a narrativa do professor: "Acredito que o maior desafio seja o desinteresse dos alunos. Prender a atenção, instigar ao conhecimento jovens que veem lá fora um mundo muito mais atrativo e divertido do que em frente a um quadro, em uma sala de aula, é uma tarefa bastante árdua".

Ao mesmo tempo em que suas narrativas informam ser esse um quadro naturalizado no cotidiano da escola, ainda têm esperanças em aproximarem-se do que poderia "atrair o interesse dos alunos". Como se fosse uma possiblidade de retomar a relação pedagógica e as concepções sobre a função da escola que perpassam as representações construídas sobre as finalidades dessa instituição de socialização. O reconhecimento de que "lá fora o mundo é mais atrativo" comunica a indicação de que a escola precisa reinventar-se, ao mesmo tempo em que expressa a impotência em fazer diferente, pois ainda não foi encontrado o caminho sobre "como fazer".

\section{A família educa e a escola ensina (?)}

No que tange ao segundo ponto, a denúncia da "ausência da família" é recorrente nas narrativas e associa-se a muitos aspectos, requisitando a retomada do papel de uma escola que, no imaginário dos professores, voltava-se exclusivamente ao que referem como "ensino" (dos conteúdos conceituais): "O maior problema é ensinar em uma época em que as famílias depositaram na escola a função de educar também. Ser um intermediador entre o ensino e a educação, essa última considerada a base, está chegando nas escolas para ser função do professor, mas isso deveria vir de casa". Essa narrativa remete à ideia de que nas responsabilidades da família, no seu papel de "educar", estariam embutidos: as funções de socialização, o trabalho com os valores, as orientações sobre as maneiras de portar-se no convívio social e as posturas de respeito à autoridade. O que evidencia a recursiva afirmativa: "A família educa e a escola ensina".

Com a escolarização obrigatória ampliada, com a reconfiguração das famílias e com a presença mais efetiva das mulheres no mundo do trabalho, reduziu-se o tempo de convívio familiar e de investimento relacional nos processos de socialização primária. Entretanto, o vazio deixado não foi preenchido e mantém-se nas requisições dos professores: "Dificuldade é os pais largarem os filhos na escola e deixarem tudo nas mãos dos professores e, ainda, acharem que os professores têm obrigação de resolver tudo". A sobrecarga do professor parece aumentar também pelo fato de que outras instituições de socialização deixaram de ocupar um papel regulador na formação das gerações mais novas, a exemplo da religião e do mundo do trabalho.

Na escola é depositada a tarefa de "educar", mencionada nas narrativas dos professores, situação que eles reclamam não ser seu papel e resistem em cumpri-lo: “O maior problema é conseguir ensinar, mas o que está em questão hoje em dia é o educar, o que seria mais função familiar. Não que não seja papel do professor também, porém está sobrecarregado sobre ele". No entanto, é a "falta de educação" advinda da família que dificulta o estabelecimento da relação pedagógica, devido ao desinteresse dos alunos em aprender, ao desrespeito às normas ou à não aceitação do ensino que a escola propõe.

Observa-se que os professores reclamam muito mais das questões atitudinais dos seus alunos do que dos aspectos propriamente cognitivos, demonstrando uma recusa em adentrar no papel que acreditam ser apenas de responsabilidade da família. Estaria instalada aí uma relação de interdependência. De um lado, os alunos não estão motivados, não respeitam normas e não fazem o que a escola propõe; de outro, a escola não consegue dar conta do seu papel de ensinar (os conteúdos). Mas os professores não querem suprir a lacuna deixada pela família que não educa seus filhos; assim, a qualidade do ensino (ou da educação) não atinge os níveis esperados, pois "muito conteúdo (informação) fica sem ser dado".

Para os professores, é a família que deve "educar", sendo a educação entendida como sinônimo de formar valores, de preparar ao convívio social para além do espaço da casa. Portanto, as crianças e os jovens deveriam chegar à escola com essas posturas desenvolvidas. Mas, segundo as narrativas produzidas, a família tem falhado em seu 
papel, transferindo para a escola a função socializadora primária. Embora a escola identifique isso como um problema que dificulta o desempenho de seu papel de ensinar e reconheça as dificuldades da família, mantém-se resistente em assumir que o "ensino dos conteúdos", além da dimensão cognitiva, envolve as dimensões atitudinais e procedimentais. Isto é, o trabalho com os valores e com as normas de convívio social, oportunizado pelo exercício permanente da cidadania.

Os professores reclamam que não conseguem dar aulas, pois "os alunos não querem nada com nada", já não os respeitam e nem observam as normas da escola. Ainda assim, recusam-se em assumir o papel de socialização secundária que a escola contemporânea tem sido "convidada" a desempenhar, notadamente relacionada à ampliação dos anos de escolarização obrigatória.

Esses novos cenários requisitam um processo de mutação da escola, fortemente evidenciado nas narrativas dos professores pela identificação da necessidade de sua reinvenção. Porémainda não visualizam o formato, sugerindo estarem aguardando que algo ou alguém, externo à escola e à relação pedagógica, apresente uma alternativa.

\section{O desafio é aturar gente que não quer saber de estudar}

O direito à educação é interpretado por alguns professores como um grande feito no processo de democratização e de desenvolvimento do país, ao mesmo tempo em que é acompanhado de muitos desafios, conforme narra uma professora: "Um avanço para a sociedade, mas um desafio para a escola, que precisa se reinventar". Essa afirmação remete à necessidade de "reinvenção da escola" e sugere a efetivação de mudanças diretas na ação docente. Entretanto, o trabalho com a diversidade sociocultural ou com uma educação para todos, inclusive para aqueles que "não querem estudar", ainda demanda investimentos, tanto na compreensão desse novo momento da educação nacional quanto na efetivação de políticas e práticas educativas que contemplem o trabalho com a diferença. Os professores, em sua maioria, denunciam um estado de desconforto com os novos cenários, evocando em suas competências docentes a habilidade de "aturar gente que não quer saber de estudar e é obrigada a ir para a escola, o que acaba prejudicando a professora e os que querem estudar".

Os ecos dessas narrativas reforçam a necessidade de discutir o paradoxo do direito à educação e à escolarização obrigatória e de estabelecer relações com o que começa a ser processado no cotidiano da escola à medida que a adesão deixa de ser espontânea para ser compulsória. É a partir de sua prática profissional nesse contexto que um dos professores da pesquisa, relata: "Percebo que os alunos têm mais direitos que deveres. Esses direitos, às vezes, prejudicam o bom andamento das aulas. Há casos de alunos que faltam o ano inteiro, mas eles têm o direito de realizar uma prova que pode ou não aprová-los. Não acho isso certo, porque eles deveriam ter também o dever de frequentar as aulas diariamente".

A consequência parece ser evidente, pois as escolas mudam o perfil majoritariamente homogêneo (acolhendo somente aqueles que tinham predisposição positiva para a socialização formal) para uma composição heterogênea, recebendo crianças e jovens de diferentes origens socioculturais. À organização da ação pedagógica é (im)posta a demanda do trabalho com a diversidade sociocultural: "A partir da Constituição Brasileira, é garantido o acesso de todos à educação, e também é obrigatório, contudo com essa obrigatoriedade vêm para a escola também aqueles que não querem nada com nada. $\mathrm{E}$ a gente tenta dar a aula de várias formas, mas eles não se prendem em nenhum momento, acabam só atrapalhando".

Para os interlocutores empíricos, o direito de uns (aqueles que querem aprender) é afetado em detrimento dos direitos de outros (aqueles que não têm a adesão pela escola). Ao mesmo tempo, manifestam a preocupação de que, se não houvesse a obrigatoriedade, o Brasil continuaria a assistir ao trabalho infantil e manteria os baixos níveis de escolarização da população: "Nesse caso atrapalha, mas ainda bem que tem o direito e a matrícula é obrigatória. Já pensou como seria se esse direito não fosse obrigatório?". Entra em pauta a discussão sobre a organização do trabalho pedagógico voltado ao respeito às diferenças, conforme a afirmação de uma das professoras entrevistadas: "É um desafio lidar com tantos alunos vindos de vários contextos sociais e culturais! Exige da gente bastante estudo, dedicação, planejamento variado. Tenho que pensar em todos eles, levar em conta a sua realidade". Outra professora afirma não conseguir "incluir todos no planejamento", indicando o desafio simultâneo em fazer a intervenção, porém respeitando a singularidade.

Ao olhar para a prática docente, os professores expressam as dificuldades que têm em "atingir a todos de forma igual, sem discriminar, e preocupando-se com a aprendizagem e com o futuro dos alunos". A educação inclusiva, representada pela inclusão do aluno com necessidades especiais em turmas regulares, apareceu com força nas narrativas dos professores: "Significa ter de trabalhar com uma diversidade muito grande de alunos, cada um com suas peculiaridades, com um sistema de ensino falho, que não investe tudo que deveria para ter uma educação de qualidade".

Ao (re)clamarem por uma resposta sobre "como fazer” (produzida externamente à relação pedagógica), os professores informam que a escola contemporânea 
continua a reproduzir o projeto moderno, voltado à centralidade na ação do professor, ao planejamento das aulas para uma turma e/ou uma faixa de idades, com indicadores coletivos de aprendizagem, sem, contudo, atender às especificidades representadas pela inclusão e pelo respeito à diferença.

\section{Tem de se cuidar muito com o que se diz e com} o que se faz, pois tudo favorece o aluno

Aliados às dificuldades em planejar ou organizar o trabalho pedagógico para as especificidades que a diferença requisita, outros dois aspectos perpassam as narrativas dos professores na reflexão que fazem dos cenários contemporâneos da atuação docente: o sentimento de constrangimento e o de perda de poder. O primeiro pode ser evidenciado nas narrativas a seguir, as quais indicam que os professores atuam em estado de vigilância (e defesa) constante, pois, em suas percepções, a atual legislação os coloca na condição de reféns da relação pedagógica: “(...) Tem que cuidar muito sobre o que diz e o que faz, porque quase tudo favorece o aluno". Os professores dizem que não querem "educar", mas essa tarefa parece estar cada vez mais delegada à escola. Se pudessem, talvez, promoveriam a "educação" - que segundo eles deveria vir de casa -, repreendendo atitudes não adequadas, porém acabam por não fazer, pois temem ser acusados de "exposição de incapaz".

Em direção semelhante, foram comuns associações ao desequilíbrio entre os direitos e os deveres dos alunos, colocando o professor em momentos de constrangimento, pois "os alunos têm mais direitos que deveres, e eles, por saberem disso, acabam abusando, muitas vezes, em suas atitudes frente ao professor". O desafio da ação docente passa então a ser "lidar com alunos que conhecem seus direitos e usam esses conhecimentos como forma de intimidar o professor".

Os colaboradores da pesquisa revelam que na experiência docente contemporânea "o professor precisa saber como agir em algumas situações para não se comprometer, pois os alunos normalmente sempre são favorecidos". Para eles, "os direitos estão muito mais acentuados que os deveres. Mas é importante conscientizar os alunos dos direitos e dos deveres de todos também, pois se não conhecer os deveres dos alunos e os direitos dos professores, o professor acaba perdendo sua autoridade e não pode mais chamar a atenção dos alunos. Não pode sequer dizer 'vira pra frente, fica quieto'. Os alunos não compreendem muito bem seus direitos $\mathrm{e}$ acabam pensando que para ter seus direitos garantidos a escola deve acatar todas as suas vontades e necessidades".

$\mathrm{O}$ estado de constrangimento percebido pelos professores perpassa pelo que entendem ser um desequilíbrio ou uma deturpação dos direitos dos alunos em relação aos deveres, especialmente aqueles inseridos no ECA. No entanto, os professores narram que não costumam trabalhar com temas como direitos humanos e cidadania, pois têm dificuldades em tal abordagem: "É um assunto pouco discutido no ambiente no qual faço parte, e pude perceber que é importante saber algo sobre esse assunto, porém é pouco trabalhado. Não sei se, mesmo sabendo mais, eu iria trabalhar em sala de aula. Acho muito complexo".

A forma como a escola procede na formação das virtudes cidadãs, dilui-se no que mencionam ser o trabalho com os valores: "Diretamente com Direitos Humanos não (trabalho), mas de outras formas, por exemplo: trabalhando valores, procuro passar o tema aos alunos". A postura de "passar aos alunos" sugere uma desconexão entre as culturas do mundo adulto e da classe social dos professores com as culturas e situação social da infância e da juventude, em um possível investimento de ordem muito mais conceitual do que propriamente relacionado à experiência cotidiana.

Os professores se dizem despreparados e deslocados dos conhecimentos conceituais e didáticos dos temas que, direta ou indiretamente, afetam sua atuação docente e que se relacionam ao que indicam ser os maiores desafios da educação contemporânea: "Percebi que muitas coisas sobre o assunto de direitos humanos já não lembro, pois faz muito tempo que terminei a faculdade e não tenho muito tempo para ler mais sobre o assunto". E ainda dizem não terem tido investimento voltado a essa questão em sua formação inicial ou continuada.

Associado ao constrangimento, outro aspecto mencionado anteriormente e presente nas narrativas reflexivas dos professores, está a sensação de perda de poder do professor e de empoderamento dos alunos. Esta fortemente relacionada à avaliação escolar, orientada pela $\mathrm{LDB}$ e não mais com características de seleção e classificação, mas de diagnóstico e de emancipação. Os professores consideram que têm muitas dificuldades em reprovar os alunos e, assim, já não podem contar com o poder regulador que era exercido pela avaliação escolar. Contudo, não sabem qual mediação utilizar para motivar os alunos.

\section{É difícil motivar o aluno com apenas caderno, quadro-negro e giz}

Os professores identificam o distanciamento entre a escola e as culturas digitais, quarto ponto que destacam em suas narrativas. Em suas falas há um reconhecimento da impotência da escola perante os novos cenários educativos, ao mesmo tempo em que são narradas práticas aproximadas à escola da reprodução, cuja ação pedagógica tem centralidade no professor, no que ele "prepara" para ser aprendido e no que a escola "escolhe" para ser ensinado: "O maior problema/desafio está sendo 
o de se adaptar com alunos que estão em constante contato com novas tecnologias e fontes de informação e, muitas vezes, ter que atrair suas atenções com apenas caderno, quadro-negro e giz. Também encontro dificuldades em despertar o interesse dos alunos pela leitura, uma vez que possuem diversos acessos às fontes de informação".

Direta ou indiretamente, os quatro pontos destacados das narrativas dos professores se entrelaçam e permitem ainda o estabelecimento de algumas relações. A par das culturas da (re) clamação ${ }^{3}$, ao expressarem as suposições que elaboram sobre as causas do desinteresse e da desmotivação dos alunos, os professores reconhecem que a escola caminha em larga desvantagem em relação à mobilização e motivação que as TICs oportunizam, especialmente as culturas digitais.

Ao mesmo tempo em que responsabilizam o aluno pelo desinteresse, reconhecem que a escola não tem dado conta de sua função como transmissora dos conhecimentos que a humanidade construiu: "Destaco a questão de manter o interesse dos alunos, conciliar a tecnologia com o cotidiano em sala de aula. Para as dificuldades, destaco o pouco envolvimento da família com os alunos, no sentido de 'cobrar' e incentivar os estudos. Percebo alguns alunos com poucos objetivos de vida, conceitos superficiais acerca de temas sociais importantes".

A informação trabalhada nas aulas, ou a leitura que a escola defende, pode ser acessada e praticada independentemente da escola. Seus recursos didáticos mostram-se pouco atrativos, e a infraestrutura precária, a organização curricular e o sistema de ensino sobrecarregam o professor com muitos alunos em aula, muitas turmas e/ou com mais de uma escola, tendo em vista também, a necessidade de ampliar a jornada de trabalho devido aos salários baixos. Além disso, as categorias socioculturais "criança e jovem", com raras exceções, ficam subsumidas à figura do aluno, remetendo ao processo de homogeneização que transversaliza as concepções, em uma invisibilidade das culturas que adentram a escola cotidianamente.

\subsection{As narrativas dos alunos 4}

Sem a pretensão de comparar as narrativas dos alunos com as dos professores, ponderando as diferenças na estrutura dos instrumentos de pesquisa, mas procurando um possível entrecruzamento do percebido sobre a

\footnotetext{
3 (Re)clamação está grafada propositalmente com parênteses no prefixo da palavra, pois intenciona vincar que, além do queixume, as narrativas dos professores carregam um clamor para que suas percepções produzam ecos.

4 Adotou-se postura distanciada das homogeneizações que acompanham as representações construídas sobre a categoria "alunos". UPara referir genericamente os discentes colaboradores da pesquisa, situando suas narrativas segundo a geração de pertencimento, acompanhada da codificação, utilizou-se: $\mathrm{EF}$ ou EM, para nível de ensino; $m$ ou $f$ para sexo; 6 ou 9 para sexto e nono ano do EF; e, respectivamente A, B, C para primeiro, segundo e terceiro anos do EM.
}

experiência docente e escolar, em ambos os segmentos, aborda-se neste item os sentidos atribuídos à escola $\mathrm{e}$ presentes nas narrativas dos alunos.

São inegáveis os avanços conquistados nas várias fases de ampliação da escolarização obrigatória no Brasil, porém ainda se assiste à grande defasagem nos fluxos de passagem entre os anos iniciais e finais do EF e EM e na transição do EF para o EM. O efeito funil pode ser percebido na amostra que compõe as análises deste texto: redução de um terço das matrículas entre o sexto e o nono ano do EF e de dois quintos entre o primeiro e o terceiro ano do EM.

A mesma tendência acompanha as motivações para ir à escola, mais aproximadas no sexto ano do EF e no primeiro ano do EM do que nos últimos anos de ambos. A transição do EF para o EM parece abrir novas perspectivas para o começo do novo e último nível da educação básica, acolhendo um olhar mais positivo do que aquele que se tinha no final do nível anterior.

\section{É bom ir para a escola, mas as aulas são entediantes}

A importância de ir para a escola é destacada nas narrativas dos participantes da pesquisa, com um grau de motivação mais elevado no sexto ano do EF e no primeiro ano do EM. Para os adolescentes do EF, o sentido projetivo da escola é referido na aprendizagem dos conteúdos e na valorização da mediação dos professores: "Se não tiver boa convivência com os professores, com quem eu vou ter?" (EFm6). O foco no ofício de aluno também aparece na expressão do mesmo adolescente: “(...) Se eu não estudar, não for um bom aluno, como vou ser na vida real?". A dimensão socializadora da escola é acentuada na referência ao que mais gostam de fazer: "trabalhos em grupo e conversar com os amigos" (EFm6). Mas, também, nos percursos que transcendem o espaço da família: “(...) pra gente não ficar tão sozinho (em casa)" (EFf9). No horizonte da vida está o ingresso na vida ativa; "Porque sem estudo não arruma trabalho" (EFm6). E a escola é uma ponte para chegar lá: "Para no futuro ter uma ficha correta, um currículo bom" (EFf6). Interessante observar as sintonias dessas narrativas com as dos jovens do primeiro ano do EM, os quais destacam as amizades, a preparação para a entrada no ensino superior e para o mundo do trabalho, como justificativas para ir à escola: “(...) É da escola que tirarei meu maior suporte para o ensino superior" (EMfA); "Na escola, aprendemos, fazemos novos amigos e somos preparados para o mercado de trabalho" (EMfA); “(...) É um lugar que me faz bem em todos os sentidos" (EMfA).

Semelhante tendência é observada nas aproximações entre as narrativas dos adolescentes/jovens do nono ano 
do EF e do terceiro ano do EM, as quais comunicam desagrados em relação à escola. A maioria dos adolescentes/ jovens do último ano do EF dizem que se pudessem escolher iriam para a escola somente para encontrar os amigos ou participar das disciplinas cujas professoras são legais. Consideram as aulas chatas e contraditórias: "Porque o cara tá quieto e elas falam pra prestar atenção" (EFm9); opinam sobre o método de ensino adotado, afirmando que as "(...) professoras que não sabem dar aula só mandam a gente copiar coisas do livro" (EFf9); e sobre o distanciamento e as relações de poder na relação pedagógica, afirmam: “(...) não gosto como tratam a gente. A professora tem um jeito de pensar muito diferente do nosso, aí a gente quer ver quem manda mais" (EFm9).

Os jovens do terceiro ano produzem justificativas dirigidas à qualidade do ensino que recebem, remetendo-se aos professores, aos seus métodos de ensino e à infraestrutura precária para expressarem o seu descontentamento: "Gosto de aprender e estudar, mas o ensino está deixando muito a desejar, com péssima qualificação do corpo docente e más instalações, com falta de laboratórios. Isso tira a motivação de vir à escola" $(\mathrm{EMmC})$; "É muita coisa desnecessária e professores desqualificados" (EMmC). A desmotivação e a falta de interesse, referidas pelos professores em relação aos alunos, ganha aqui o sentido inverso, atribuindo a esses a impotência em tornar as aulas mais agradáveis: "Sou pouco motivada pelos professores. Ees não passam mais interesse em nos passar conteúdo" (EMfC); "Sou pouco motivada, pois muitos professores chegam na sala de aula sem conteúdo nenhum para dar" (EMfC).

O término de uma etapa na trajetória de formação, o EF ou o EM, parece produzir fadiga: “(...) Estou um pouco cansada de escola já" (EMfC). E isso aumenta o distanciamento entre a escola desejada e a praticada. $\mathrm{O}$ manifesto desagrado em "ficar sentado várias horas fazendo a mesma coisa" (EFm9) reforça o destaque aos passeios e aulas de Educação Física. Além da entrada, intervalos e saída das aulas, como os momentos mais felizes na experiência escolar. Esses adolescentes/jovens manifestam que demandam aulas mais qualificadas e professores mais preparados para o atendimento de suas necessidades de aprendizagem. As "aulas legais", em geral, associam-se ao bom desempenho dos jovens - "entendo e me dou bem na matéria" - e, também, à performance do professor, ao seu humor, ao grau de profundidade com que aborda os conteúdos, à tolerância que têm com as culturas que perpassam a composição da turma.

\section{A escola deve ser mais amiga}

As queixas sobre os distanciamentos na relação pedagógica entre professores e alunos é ressaltada nas narrativas construídas para justificar a insatisfação quanto à frequência e à participação das aulas, de modo gradativo ao longo dos três anos do EM, atingindo 95\% de insatisfação no terceiro ano. Sugestões para tornar a escola mais atraente e para mudar a relação pedagógica são as mais destacadas nas narrativas desses jovens.

O primeiro ano reclama por "uma atenção mais individualizada" (EMfA) e requisita abertura ao diálogo, pois acredita que "falta um pouco de comunicação, e os alunos também têm opiniões sobre a escola" (EMfA). Reivindica, também, espaço de expressão e manifesta o desejo por aulas diferentes: "A escola deve ser mais amiga, fazer coisas, gincanas, atividades legais que interessem os jovens, a escola deve ser um lugar onde ninguém tem preguiça de ir, ser mais interessante" (EMfA). Além disso, requisita espaço de expressão, pois percebe que "os alunos não sentem vontade de vir à escola por conta da direção, pois são muito exigentes e não dão espaço para o aluno se expressar" (EMfA).

Os jovens do segundo ano, por sua vez, reconhecem que "hoje em dia, falta respeito de ambas as partes" (EMfB) e dizem que todos os envolvidos são responsáveis, mas a iniciativa deveria partir dos professores: "Acho que a escola deveria ser menos rude e tentar se aproximar dos alunos e os mesmos deveriam corresponder positivamente" (EMfB).

Já os participantes do terceiro ano são mais enfáticos e direcionam suas narrativas à falência de um modelo de escola que segue sendo reproduzido, embora os indicadores de seu esgotamento demonstrem não haver mais espaço para ela. A denúncia ao método cópia-responde é uma dessas evidências: "Passamos horas escrevendo coisas em nosso caderno (cópias do quadro) e a parte prática é quase nula. Precisamos renovar nosso ensino! Ainda se fazem coisas que se faziam há 200 anos atrás!" (EMmC).

As narrativas desses jovens repercutem que outros direitos decorrem do direito à educação para além do acesso. A experiência escolar gera a falta do direito ao diálogo e ao respeito às diferenças. Entre as sugestões para reinventar a escola expressam: “(...) a parte em que professores e direção ouviriam mais os alunos e a escola promovesse mais atividades" (EMfC); "sugeriria aulas diferentes que não fossem sempre do mesmo método: "copia/responde"" (EMmC); "ir se adaptando conforme os anos vão passando, modernizando o ensino" (EMmC).

A reflexão crítica sobre a experiência escolar formulada pelos alunos do terceiro ano reclama uma atualização dos métodos de ensino perante os novos contextos envolvidos nos processos de socialização dos jovens. Além de requisitar o lugar da fala para efetivação dos princípios constantes na LDB e no Projeto Pedagógico das escolas relativamente às práticas democráticas, permeadas pela escuta do que os alunos têm a dizer, ou seja, pautadas pelo diálogo. A ausência do uso das TICs 
não é mencionada de modo direto, indicando que o acesso à informação por outros meios que não somente a escola está absorvido e naturalizado entre os alunos.

\section{A escola e sua promessa não cumprida}

Reproduzida nas narrativas dos alunos que destacam a importância da escola em suas trajetórias, a escola das promessas assume outra imagem quando a reflexão sobre a experiência escolar é desafiada, indicando uma expectativa criada, mas frustrada para a maioria.

$\mathrm{O}$ senso de não cumprimento de suas expectativas por parte da escola atinge $41 \%$ dos jovens do primeiro ano, cresce para $55 \%$ no segundo ano e alcança $85 \%$ no terceiro ano, sublinhando o distanciamento que vai sendo produzido ao longo desses três anos e ao final da escolarização. A mesma tendência se mostra nas narrativas dos adolescentes, entre o sexto e o nono ano do EF, passando de uma expectativa positiva de mais de $90 \%$ para uma negativa em torno de $50 \%$.

Uma jovem do primeiro ano menciona a homogeneização no tratamento às especificidades, pois "muitas vezes tratam o aluno como um todo e não dão atenção a ele" (EMfA). Os jovens do segundo e do terceiro ano reclamam da falta de diálogo, relacionada com ausência de espaços para a participação, a exemplo da extinção do Grêmio Estudantil, associativismo presente nos projetos pedagógicos das escolas e assegurado pela legislação. Os jovens de mais idade, provavelmente mais autônomos, são os que mais problematizam a formação dos professores, o método de ensino e a qualidade da educação que recebem: "Quando comparo nosso ensino com os outros países, sinto-me uma criança, aprendo conteúdo de $8^{\mathrm{a}}$ série do ginásio americano no 3 o ano do ensino médio" (EMmC); "porque para eles (os professores) está sendo 'tanto faz como fez', e não é isso que eu esperava e nem o que preciso" (EMfC). Referem a indiferença para com suas necessidades específicas, afirmando que a "escola pública não enxerga aluno inteligente, ela trata todos sem atenção, formando pessoas que não sabem $1 / 3$ do que aprendem" (EMfC). De outro lado, expressam que os alunos com dificuldades são invisíveis aos olhos dos professores e que as soluções às dúvidas são buscadas individualmente $\mathrm{e}$ não podem depender da explicação dos professores, pois "tem matérias que não entendo nada, a explicação não é legível" (EMfB). Eles requisitam atendimento e trabalho voltado às diferenças, querem ser escutados e almejam uma virada pedagógica nos modos de fazer a aula e no relacionamento dos professores para com os alunos.

\section{Interconectando narrativas (de professores e de alunos)}

As culturas da reclamação presentes nas narrativas de professores e de alunos caminham em rotas distintas, cujos possíveis pontos de intersecção se evidenciam na necessidade de (re)constituição da relação pedagógica.

Se a escola é um direito e uma obrigação; se os conceitos de educação e de ensino se confundem, atravessam-se e se complementam; se as fronteiras entre os papéis da família e da escola já não são nítidos; se os professores percebem que os alunos não querem nada com nada e estes, em outra ótica, dizem que querem uma escola que os motive e que os escute; se os professores não conseguem exercer a autonomia que lhes foi atribuída nos novos cenários educativos; e se os alunos, ao contrário, exercem-na, ousando formular suas percepções sobre o que consideram ser problemático em sua experiência escolar; e se muitas outras hipóteses fossem formuladas... Então, não se pode permanecer indiferente perante esses ecosproduzidos pelas narrativas de professores e alunos sobre a escola e sobre a relação pedagógica.

\section{ECOS DO PERCEBIDO (POR PROFESSORES E JOVENS) SOBRE A RELAÇÃo PEDAGóGICA}

Muitos são os referentes a serem evocados na tarefa de interpretar os ecos das palavras dos interlocutores empíricos que colaboram nas relações aspiradas no texto. É inegável que a escola como instituição de socialização passa por uma crise de sentidos, a qual afeta diretamente a experiência docente e escolar, evidenciando as culturas da (re)clamação que perpassam o cotidiano escolar.

Embora um conjunto de fatores de ordem social, política e econômica, externos à escola, possam ser relacionados, indicando estarmos vivendo um processo de declive das instituições, esta abordagem volta-se para o vivido e para o percebido no interior da escola. Assim, neste item, ocupa-se em desenvolver alguns aspectos de natureza cultural que emergiram dos dados empíricos.

\section{Dicotomia entre o saber e a relação}

A crise da escola que acompanha as narrativas dos professores e alunos participantes da pesquisa pode ser analisada a partir de pelo menos dois pontos de observação.

No caso dos professores, a crise é produzida por um atravessamento em suas certezas relativas à reprodução da histórica forma escolar, mostrando que seu saber fazer já não dá conta das necessidades e expectativas do cotidiano. Para além do que se passa no social e que afeta o pedagógico, ousa-se afirmar que um dos eventos desencadeadores da percepção da crise pode ser o direito à educação que, como um direito humano, incide na legislação brasileira como direito social, culminando na democratização do acesso e escolarização obrigatória, acolhendo a diversidade sociocultural. 
Da parte dos alunos, a crise pode ser identificada pelo exercício do senso crítico; pela pronúncia da palavra que informa a frustração das expectativas em relação às promessas não cumpridas pelo projeto moderno de escola; pela força das culturas que adentram a escola e desestabilizam práticas distanciadas de diálogo; pelo reposicionamento na relação pedagógica, saindo de uma postura passiva em direção à manifestação do desejo por uma participação ativa e interativa.

É a crise que desafia a mutação da escola, a qual não cabe mais em uma forma (com sentido de molde), mas, ao contrário, é desafiada a protagonizar seu papel em cenários de incertezas ${ }^{5}$. Talvez a escola contemporânea esteja colhendo os frutos do princípio amplamente divulgado nas décadas de 1980 e 1990 e presente nos projetos pedagógicos das escolas até hoje. Isso porque os adolescentes/jovens estão mostrando-se sujeitos ativos de seu processo, (re)clamando por uma escola que atenda às suas expectativas, nem que para isso tenham de ter atitudes desencantadas, resistentes ou distanciadas.

Ambos, professores e alunos, têm consciência da crise e da necessidade de mutação, porém não encontram pontos de conexão. É a natureza da relação pedagógica praticada que parece estar no limiar dos distanciamentos observados.

Conforme situa Fonseca (2008, p. 366), “a relação pedagógica implica interações humanas e psicológicas, de confiança e de respeito intelectual". Evocando Bachelard, a autora acrescenta que a relação pedagógica exige posturas intencionais do professor com fins no desenvolvimento intelectual dos alunos, como "um desejo de que o aluno possa superar o mestre" (p.366). Nessa direção, o professor seria "muito menos alguém que ensina e mais alguém que desperta, estimula, provoca, questiona e se deixa questionar" (p.367). Esse parece ser um ponto de tensão nas relações pedagógicas estabelecidas nos contextos do vivido pelos interlocutores empíricos do estudo em análise. Ao insistirem na difusão de um modelo cultural ditado por forças externas à relação pedagógica, no desejo explícito de centrarem suas práticas na separação entre "educação" e "ensino", os professores transitam na contramão do que postula Certeau (2012, p. 129), ao dizer que "é impossível aceitar, até mesmo na escola, uma tal separação entre o saber e a relação".

Talvez essa dicotomia seja responsável pela produção do sentimento de impotência narrado pelos professores, indicando que a mutação reivindicada pela escola contemporânea tem de considerar "os indícios de um novo papel da escola" e lembrar que "quanto mais o saber

\footnotetext{
5 A tríade escola das certezas, das promessas e das incertezas é uma categoria analítica tomada emprestada de Canário (2006), que, ao problematizar o futuro da escola, evidencia o processo de mutação requerido na contemporaneidade.
}

se marginaliza, mais os problemas de relação invadem o campo que ele ocupava" (CERTEAU, 2012, p. 128). A escola já não tem a hegemonia na transmissão do conhecimento construído pela humanidade, pois novos agentes concorrem na socialização das novas gerações. No entanto, é depositada na escola e no trabalho docente a solução para os problemas da sociedade, entre os quais, uma redefinição da cultura e da integração da juventude. Todavia, recorrendo outra vez a Certeau (2012, p.130-131), “o docente flutua à superfície da cultura: ele se coloca na defensiva à mesma proporção em que se percebe mais frágil. Torna-se inflexível. É levado a reforçar o rigor da lei das fronteiras de um império do qual não está mais seguro".

Em outras palavras, os professores informam que o direito à educação - regulado entre outros aspectos, pela escolarização obrigatória - "desarruma" suas práticas e, muitas vezes, fazem deles reféns de um processo. Eles suspeitam de que o seu poder está abalado e que não mais os sustenta. Testemunham uma mutação global nos quadros de referência que os coloca como prisioneiros e cúmplices de uma situação, "na medida em que têm a ilusão de crer que possuem ou que deveriam possuir 'valores' para distribuir" (CERTEAU, 2012, p. 134).

De sua parte, os adolescentes/jovens parecem centrar atenção e atribuir valor justamente na relação, sendo o saber uma consequência. Eles referem a escola como agente de transição que, em muitos casos, propicia seus trânsitos para a vida ativa. Mas, ao mesmo tempo, reivindicam que seja um tempo e um espaço de exercício de cidadania, através do qual acreditam ter o que dizer e com o que contribuir para a escola se aproximar de suas expectativas. Talvez os ecos das narrativas dos alunos informem que eles resistem em assistir à cultura sendo silenciada ou expulsa do ensino, pois é através dela que constituem suas identidades geracionais, individuais e coletivas, em uma concepção implícita de que toda atividade humana pode ser considerada cultura. Todavia, alerta Certeau (2012, p. 141), "ela não o é necessariamente ou não é ainda forçosamente reconhecida como tal".

Embora o respeito à diversidade sociocultural esteja explícito na legislação educacional brasileira, ainda é um elemento importante para a reflexão, porquanto continua ecoando práticas e concepções que entram em rotas de colisão com o que preconiza a lei e, de modo especial, o que orienta a educação para a cidadania.

\section{Representações, práticas e táticas que permeiam a mutação da escola}

Insiste-se no desencontro entre o que os professores e os alunos relatam sobre a experiência docente e escolar. As narrativas de ambos os segmentos manifestam as representações que constroem sobre a relação pedagógica, 
as quais acabam determinando suas práticas no interior e no exterior da relação.

Nesse ponto, consideram-se as contribuições de Chartier (1990, p. 18), ao conceber as "representações como as matrizes de discursos e de práticas diferenciadas (...) que têm por objectivo a construção do mundo social, e como tal a definição contraditória das identidades - tanto a dos outros como a sua". Assim sendo, os professores possuem entendimentos sobre a adesão dos alunos à escola - "eles não querem nada com nada" - que não coincidem com o que estes têm sobre a experiência escolar: "As aulas são entediantes"; "os professores não escutam os alunos"; "os métodos de ensino são ultrapassados". Ao mesmo tempo, um discurso de vitimização do professor pela impotência em promover a mutação os coloca em uma posição passiva, naturalizando a relação pedagógica conflituosa e, muitas vezes, reproduzindo um discurso que degrada a profissão docente. Em sentido oposto, as representações dos alunos referem que eles querem estudar e desejam uma escola que atenda às suas expectativas, que os motive a frequentar as aulas e que abra canais de diálogo. Da mesma forma que os professores, os alunos reproduzem um discurso de desconstituição do professor como referente intelectual, considerado despreparado para atuar nos atuais contextos em que a cultura é requisitada para compor o ensino, principalmente no que se refere à comunicação.

"As representações não são simples imagens, verídicas ou enganosas, do mundo social. Elas têm uma energia própria que persuade seus leitores ou seus espectadores que o real corresponde efetivamente ao que elas dizem ou mostram" (CHARTIER, 2011, p. 27). Sendo assim, as representações que perpassam o percebido, narrado pelos professores e alunos sobre a experiência docente e escolar, influenciam a maneira como cada segmento se coloca na relação pedagógica e como organiza suas práticas cotidianas, na organização do ensino, no ofício de professor e de aluno, mediados pela forma escolar e pelo contexto social.

Cada segmento vai, ao seu termo, construindo modos de (sobre)viver à configuração social que se forma no interior da escola, a qual é permeável ao que se passa no cotidiano interno e externo à instituição, forçando sua mutação. Os modos de (sobre)viver à relação pedagógica desencontrada podem ser conectados às táticas referidas por Certeau, associadas às atitudes de "antidisciplina" perante o que preconiza o concebido: na legislação, nas normas da escola, nos papéis das instituições escola e família, no esperado sobre as boas maneiras (vindas de casa) dos alunos.

As práticas narradas são de difícil apreensão. O esforço analítico que se procura fazer tenta apreendê-las como ecos do percebido, o qual indica de modo nebuloso algumas táticas adotadas para (sobre)vivência. Os professores recuam no papel socializador da escola, ao mesmo tempo em que denunciam o vazio que consideram ter sido deixado pela ausência da família. Eles entendem que o trabalho com a diversidade sociocultural exigiria um planejamento distinto em respeito à diferença e ao atendimento às especificidades, porém, em suas táticas cotidianas, o trabalho coletivo, embora impotente, é o que os "salva". Se são obrigados a receber todos na escola, inclusive aqueles que não querem estudar, ao mesmo tempo em que reconhecem a importância da obrigatoriedade para o desenvolvimento do país, por vezes adotam atitudes de relaxação nas exigências ao cumprimento às normas. E, por outras, aumentam a severidade, produzindo uma ambiguidade nos modos de observar dos alunos que reclamam de uma e de outra atitude, possivelmente por esperarem um equilíbrio entre ambas.

De parte dos alunos, as táticas ${ }^{6}$ de (sobre)vivência à relação pedagógica e ao paradoxo que lhes confere o direito à escola, ao mesmo tempo em que os obrigam à frequência, convertem o espaço escolar em um lugar para encontrar os amigos, sair de casa, construir suas identidades. O sentimento de tédio ou o cansaço pelos anos de frequência se manifesta em atitudes distanciadas as quais são percebidas pelos professores como afronta, desinteresse, quebra de hierarquias.

As identidades de aluno concorrem com as identidades de adolescentes/jovens, e a escola, com seu aparato organizativo, é palco de negociações entre uma e outra. Assim, pode-se afirmar que a escola tenta (con)formar a juventude e, em certa medida, as culturas juvenis que acompanham os alunos tentam (con)formar a escola (DAYRELL, 2007). A esse processo relacional pode-se associar a teoria do processo civilizador desenvolvida por Norbert Elias (2011). Já que, no processo de relaxação e de severidade, assim como nas atitudes de rebeldia e de apatia dos alunos, é possível identificar uma configuração social produzida pelas relações de interdependência em que professores e alunos estão envolvidos por meio da relação pedagógica que estabelecem, pela atribuição que fazem ao outro como gerador de seus problemas ou para a solução dos mesmos.

\section{Configuração social e redes de interdependência na relação pedagógica}

Tomando um distanciamento das percepções sobre o vivido, presente nas narrativas, observa-se uma configuração social que circunda e transversaliza a relação pedagógica, fortalecendo a associação com os

\footnotetext{
${ }^{6}$ Certeau associa o conceito de estratégia ao poder hegemônico e dominante, como forma de convencimento do forte sobre o fraco. A tática é a arte do fraco e tem possibilidades de produzir efeitos de astúcia.
} 
estudos de Elias sobre o processo civilizador, aqui tomado em pequena escala, pois considera-se a escola e não toda a sociedade. Além do mais, trabalha-se com um recorte temporal limitado circunscrito a marcadores legais da educação brasileira. É nessa escala espaço-temporal que as tendências "podem se entrecruzar, avançar e recuar, relaxar ou apertar (...)" (ELIAS, 2011, p. 179).

Elias refere que cada um se constrói na relação com o outro, o que parece não estar sendo compreendido na escola e no vivido na relação pedagógica que dela emerge, pois as representações que têm os professores e os alunos produzem comportamentos que vão (con)formando as relações sociais e (re)produzindo a forma escolar. Entra aqui a conexão com a autonomia relativa para alteração do quadro percebido.

A experiência - docente e escolar - é o ponto de ligação entre os atores da escola, oportunizada por redes de interdependências. São essas redes que Elias afirma serem os nexos do que ele denomina de "configuração". Nas palavras do autor, o entendimento do termo estaria associado a "(...) uma estrutura de pessoas mutuamente orientadas e dependentes. Uma vez que as pessoas são mutuamente dependentes entre si, inicialmente por meio da natureza e mais tarde através da aprendizagem social, da educação, socialização e necessidades recíprocas socialmente geradas, elas existem, poderíamos nos arriscar a dizer, apenas como pluralidades, apenas como configurações" (ELIAS, 2011, p. 240). Assim, se são as relações estabelecidas entre as pessoas que "formam" a escola que determinam sua configuração, e se essas relações encontram-se extremadas, a configuração escolar por elas formada pode ser conflituosa. A recorrência nas narrativas evocadas na pesquisa, de que a situação da escola se deve ao comportamento do outro, seja ele professor ou aluno, demonstra isso.

Considerando a ideia de Elias (2011, p. 178) de que o autocontrole habitual se dá "desde a tenra idade no indivíduo", pela estrutura da vida social, pela pressão das instituições e por órgãos da sociedade, em especial a família, pode-se encontrar uma base para o argumento de que a falta de autocontrole dos comportamentos no espaço escolar se deve por uma relaxação da regulação da família e por uma impossibilidade - diante do imposto/ regulado pelo ECA - da instituição escolar em fazer com que certas regras comportamentais sejam cumpridas.

Uma última questão, sobre o embate entre professores e alunos que supõem sempre estar no outro a situação caótica do cotidiano escolar, pode ser ligada tanto à ideia de configuração como à ideia de interdependência de Elias. Parece ser a partir dessa relação tensa que se configura o atual cenário escolar, pois, enquanto a escola contar com os professores que os estudantes disseram ter e com os alunos que os professores disseram encontrar, haverá na escola a mesma situação. Cada um desses personagens, como em uma rede, depende do outro: seja para aprender ou para ensinar.

\section{CONSIDERAÇõES FINAIS}

As primeiras análises dos dados da pesquisa informam que o direito à educação é garantido pelo acesso. Porém, o sucesso (e a permanência) tem se mostrado distante de um contingente significativo de crianças e jovens brasileiros, talvez pela simplificação das próprias concepções desse direito humano, traduzido no vivido das instituições, quase que, exclusivamente, pela criação de vagas e pela efetivação das matrículas.

Embora com restrições ao trabalho com a diversidade sociocultural, os professores acabam por acolher o contingente de alunos que, talvez, sem a obrigatoriedade da frequência à escola por força da lei, estivesse compondo as estatísticas da população não escolarizada. No entanto, percebe-se que a intervenção pedagógica, no sentido de garantir a aprendizagem, mostra-se pouco eficaz. Uma vez que os professores organizam o ensino para um coletivo, tendo muitas dificuldades para a intervenção nas especificidades dos modos e dos tempos de aprendizagem dos alunos. É quase inexistente, pode-se dizer, o trabalho em respeito às culturas da diferença.

Outro ponto a destacar, refere-se ao como fazer, sempre presente nas narrativas dos professores, pois as sonhadas receitas para tratar os problemas não funcionam para o acelerado processo de mutação pelo qual a escola vem passando. Em possíveis respostas às culturas da reclamação presentes nas narrativas dos professores, estaria a necessidade de olhar para o conjunto de direitos que se desdobram no direito à educação, tanto nas trajetórias dos professores quanto nas dos alunos e das instituições.

Em outra via, estão as narrativas dos alunos informando sentidos projetivos à experiência escolar como transição e obtenção das credenciais para ingresso na vida ativa; e, ao mesmo tempo, sublinhando a passagem pela escola como momento intenso de afirmação identitária através das sociabilidades. Logo, fortalecendo o valor atribuído à relação pedagógica.

Uma formação inicial e continuada sobre os novos contextos educativos talvez seja um direito indireto que se entrelaça às trajetórias dos professores. Por sua vez, o respeito à diversidade sociocultural que os constitui é um direito que se desdobra nas trajetórias dos alunos, requisitando práticas pedagógicas que considerem a cultura e os saberes de experiência feitos como elementos primeiros para o trabalho da escola, sem, contudo, descuidar dos saberes formais.

Além das (inter)relações que se procurou tecer no texto, pode-se ainda recorrer a Candau (2014) e referir 
a mutação da escola como um processo que se produz também por uma mutação cultural, no interior do qual a relação com o outro ganha novos contornos. Os outros são os que se confrontam com diferentes maneira de se situar no mundo. No caso dos resultados da pesquisa, a maneira como se situam professor e aluno na relação pedagógica.

A mutação da escola como um fenômeno que emerge de uma configuração escolar sublinhada pela diversidade sociocultural, na qual professor e aluno são requisitados e/ou considerados sujeitos socioculturais, sugere a necessidade de uma negociação cultural. As culturas que acompanham os cenários e os desafios contemporâneos da educação, especialmente da educação escolar, demandam a observação da dimensão microssociológica da relação pedagógica, conforme ecos dos dados empíricos aqui apresentados. Ao mesmo tempo, numa dimensão macrossociológica, essas culturas conectam-se com os contextos mais amplos que permeiam e transitam as fronteiras da escola. Entre os aspectos endógenos e exógenos implicados no cotidiano escolar, é preciso lembrar que no horizonte está o papel político e socializador da escola, não obstante os usos que os seus atores fazem dela. Uma vez que concebido, vivido e percebido acontecem de modo pulsante e entrelaçado, separados neste texto apenas para fins analíticos.

\section{REFERÊNCIAS}

BOBBIO, Norberto. A era dos direitos. Rio de Janeiro: Campus, 1992.
CANÁRIO, Rui. A escola tem futuro? Das promessas às incertezas. Porto Alegre: Artmed, 2006.

CANDAU, Vera Maria Ferrão. Ser professor/a hoje: novos confrontos entre saberes, culturas e práticas. Educação, Porto Alegre, v. 37, n. 1, p. 33-41, jan./abr., 2014. https:/doi. org/10.15448/1981-2582.2014.1.15003

CERTEAU, Michel de. A cultura na escola. In: CERTEAU, Michel. A cultura no plural. Campinas: Papirus, 2012. p. 123-144.

CHARTIER, Roger. A história cultural: entre práticas e representações. Lisboa: Difel, 1990.

CHARTIER, Roger. Uma trajetória intelectual: livros, leituras, literaturas. In: ROCHA, João Cezar de Castro (Org.). Roger Chartier - a força das representações: história e ficção. Chapecó: Argos, 2011. p. 27.

CURY, Carlos Roberto Jamil. Direito à educação: direito à igualdade, direito à diferença. Cadernos de Pesquisa, n. 116, p. 245-262, 2002.

DAYRELL, Juarez. A escola faz juventudes? Reflexos sobre a socialização juvenil. Revista Educação \& Sociedade, Campinas, v. 28, n. 100, p. 105-111, out. 2007.

ELIAS, Norbert. O processo civilizador: uma história dos costumes. Tradução de Ruy Jungmann. 2. ed. Rio de Janeiro: Zahar, 2011.

LEFEBVRE, Henri. Everyday life in the modern world. Translatad by Sacha Rabinovitch. London: Penguin, 1971.

McCOWAN, T. O direito universal à educação: silêncios, riscos e possibilidades. Práxis Educativa, Ponta Grossa, v. 6, n. 1, p. 9-20, jan./jun. 2011. https:/doi.org/10.5212/ PraxEduc.v.6i1.0001

Submetido em 08/06/2015 Aprovado em 17/02/2016 